JOURNAL OF SYNCHROTRON RADIATION
Received 19 June 2020

Accepted 19 June 2020

Edited by R. W. Strange, University of Essex, UK

Keywords: Fe XANES; energy calibration mid-ocean ridge basalt (MORB); RGM-2; rhyolite; Havre pumice

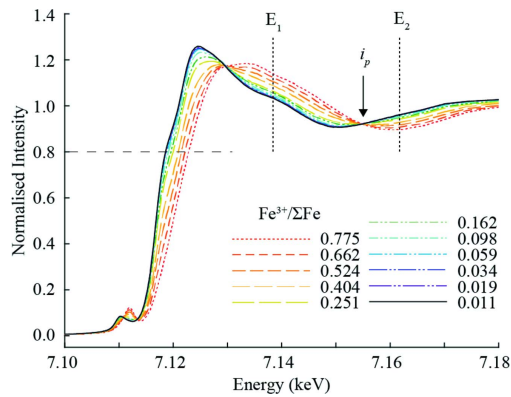

C 2020 International Union of Crystallography

\section{Iterative energy self-calibration of Fe XANES spectra. Erratum}

\author{
Michael W. M. Jones, ${ }^{\text {a* Guilherme Mallmann, }}{ }^{\text {b Jeremy L. Wykes, }}{ }^{\mathrm{c}}$ Joseph Knafelc, ${ }^{\mathrm{d}}$ \\ Scott E. Bryan ${ }^{\text {d }}$ and Daryl L. Howard ${ }^{\mathrm{C}}$
}

\begin{abstract}
anstitute for Future Environments, Central Analytical Research Facility, Queensland University of Technology, Brisbane, Australia, ${ }^{\mathbf{b}}$ Research School of Earth Sciences, Australian National University, Canberra, Australia, ${ }^{\mathbf{c} A N S T O}$ Australian Synchrotron, Clayton, Australia, and ${ }^{\mathbf{d}}$ School of Earth, Environmental and Biological Sciences, Queensland University of Technology, Brisbane, Australia. *Correspondence e-mail: mw.jones@qut.edu.au
\end{abstract}

A correction is made to the paper by Jones et al. (2020). [J. Synchrotron Rad. 27, 207-211].

In the paper by Jones et al. (2020), the authors have noted that an incorrect value was published for the calibrated $\mathrm{Fe}^{3+} / \Sigma \mathrm{Fe}$ for the rafted pumice sample from the 2012 Havre eruption. The correct value is $0.257(0.010)$ and is included in the updated Table 2 below and updated in the inset in Fig. 3(c) (overleaf).

Table 2

Summary of uncalibrated and self-calibrated values for the data presented in Fig. 3, where the uncalibrated, self-calibrated and expected $\mathrm{Fe}^{3+} / \Sigma \mathrm{Fe}$ ratios are presented together with the required energy change $(\Delta E)$.

\begin{tabular}{lllll}
\hline & $\mathrm{Fe}^{3+} / \Sigma \mathrm{Fe}$ & & \\
\cline { 2 - 4 } Sample & Uncalibrated & Self-calibrated & Expected & $\Delta E(\mathrm{eV})$ \\
\hline MORB VG3450 & $0.591(0.018)$ & $0.129(0.004)$ & 0.132 & 0.8 \\
RGM-2 & $0.535(0.037) \dagger$ & $0.231(0.016)$ & $0.262(0.015) \ddagger$ & $0.3 \S$ \\
Havre pumice & $0.452(0.031) \dagger$ & $0.257(0.010)$ & - & $0.5 \S$ \\
\hline $\begin{array}{l}\dagger \text { Manually offset to be within calibration range. } \\
\text { offset. }\end{array}$
\end{tabular}

\section{References}

Berry, A. J., Stewart, G. A., O'Neill, H. St C., Mallmann, G. \& Mosselmans, J. F. W. (2018). Earth Planet. Sci. Lett. 483, 114-123. Cottrell, E., Kelley, K. A., Lanzirotti, A. \& Fischer, R. A. (2009). Chem. Geol. 268, 167-179.

Jones, M. W. M., Mallmann, G., Wykes, J. L., Knafelc, J., Bryan, S. E. \& Howard, D. L. (2020). J. Synchrotron Rad. 27, 207-211. 

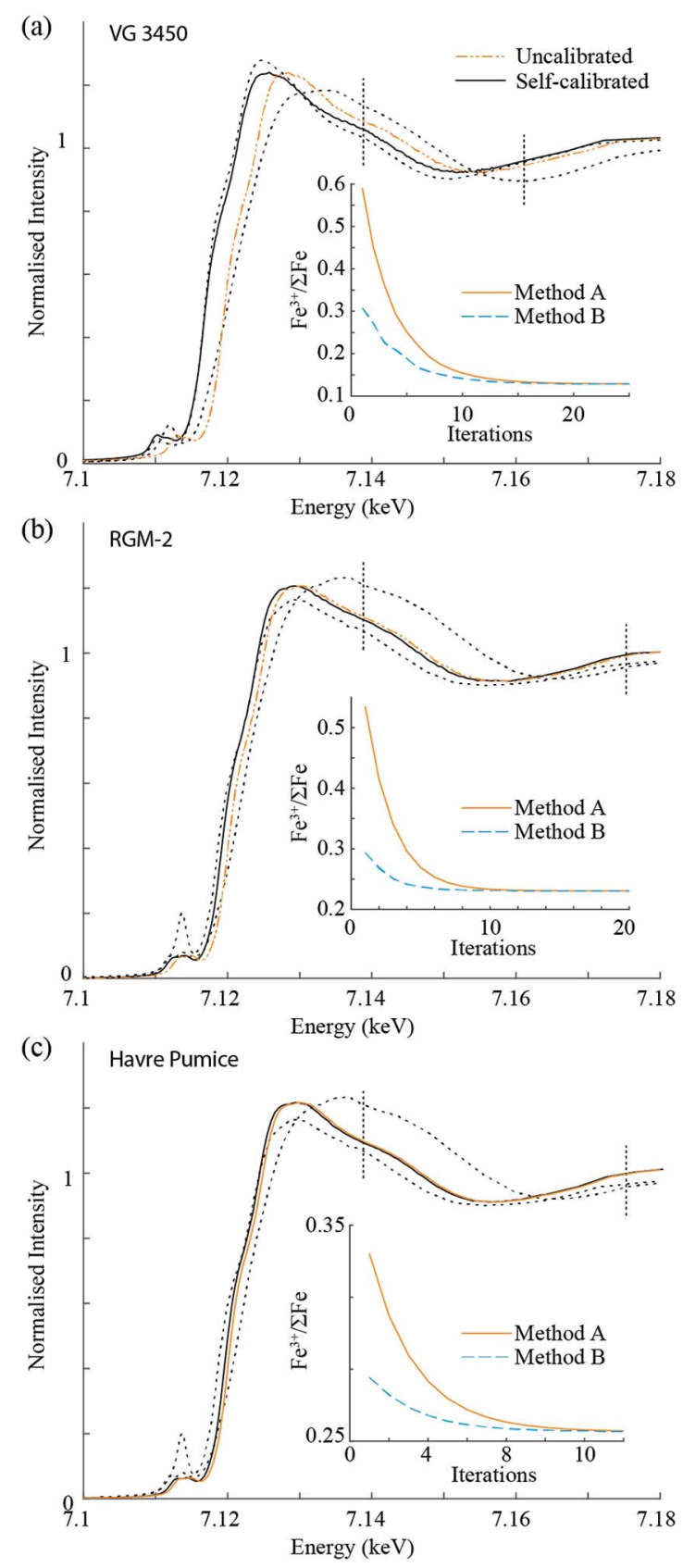

Figure 3

Demonstration of iterative energy calibration correction. (a) A MORB glass spectra (Smithsonian Institute sample number VG 3450), as collected by Berry et al. (2018) (orange dot-dashed line), iteratively self-corrected (solid black line) to the basaltic glass standards. Also shown for reference are the spectra for the 0.011 and $0.775 \mathrm{Fe}^{3+} / \Sigma \mathrm{Fe}$ ratio standards (black dotted lines). The $\mathrm{Fe}^{3+} / \Sigma \mathrm{Fe}$ ratio (inset) for Method A (solid orange lines) and B (dashed blue lines) as a function of iteration number shows convergence to a single $\mathrm{Fe}^{3+} / \Sigma \mathrm{Fe}$ ratio. Similar treatment is shown for the RGM-2 reference standard $(b)$ and an experimental section of pumice from the 2012 Havre eruption (c), both iteratively selfcorrected to the rhyolite glass standards (Cottrell et al., 2009). Also shown for reference are the spectra for the 0.238 and $0.806 \mathrm{Fe}^{3+} / \Sigma \mathrm{Fe}$ ratio standards (black dotted lines). The vertical dashed lines in $(a)-(c)$ refer to the two points $E_{1}$ and $E_{2}$ in each case. 